\title{
Development of Augmented Reality Application for Learning Computer Network Device
}

\author{
https://doi.org/10.3991/ijim.v15i12.21993 \\ Muhammad Luthfi Hamzah $(\bowtie)$ \\ Universitas Islam Negeri Sultan Syarif Kasim Riau, \\ Pekanbaru, Indonesia \\ muhammad.luthfi@uin-suska.ac.id \\ Ambiyar, Fahmi Rizal, Wakhinuddin Simatupang, \\ Dedy Irfan, Refdinal \\ Universitas Negeri Padang, Padang, Indonesia
}

\begin{abstract}
Applied augmented reality works by detecting imageries or pictures, normally called markers, by using smartphone camera that detects these preplaced markers. Augmented reality has seen wide application in various fields, one of them is education. In the field of education, augmented reality is utilized to make learning process more engaging and attractive. Starting from the problem that learning computer networks on introduce to network device which is currently still delivered conventionally. So, this research makes a solution to this problem by developing learning media using augmented reality (AR) technology, which is a technology that combines two-dimensional or three-dimensional virtual objects into a real environment and then projects these virtual objects in real time. The purpose of this research is to build AR-based applications in learning computer network devices in order to increase understanding, generate motivation and student interest. The methodology used in this research consist of Envisioning Phase (Problem Identification, Planning Phase (Planning), Developing Phase (Design), Stabilizing Phase (Testing), Deploying Phase (Implementation). This study uses 31 students as sample and the data was analysed using the SUS (System Usability Scale). The result show evaluates the usability using SUS of 31 respondents and it can be concluded that this AR application can be accepted by these students in its use with SUS Score obtained was 78.5 .
\end{abstract}

Keywords - Augmented Reality, 3D, Computer Networking Devices, System Usability Scale

\section{$1 \quad$ Introduction}

Computers and technology are the leading factors behind the shrinkage of world. Through computer network, people are able to communicate with others in faraway places, so are students and teachers, they can communicate through computer network such as email. Teachers spearhead the use of instructional technology through the use 
of computer network. With a modem and computer, one can meet with science educators with common interests in almost any region of the country or the world, 24 hours a day. Hundreds of local, regional, national and international computer networks use account and password system. Previous studies showed that there are three aspects of computer network that are successfully utilized in learning process, namely: (1) The involvement of users in a system; (2) Active email support; and (3) Occasional faceto-face meetings between users. Computer networks will expand education[1].

Computer networks are a compulsory subject studied in the field of computer science both in the Department of Informatics, Information Technology, and Information Systems. This course aims so that every student can understand and practice material ranging from the concept of computer networks to designing a topology, calculating IP subnetting and also can operate the network so that it is connected to each other using devices such as routers, switches, computers.

Teaching computer network course to students is always challenging for educators because this course requires practical understanding more than theoretical one. The major issue with this topic is that during theoretical teaching, students feel very technical. The substance of the subject matter is another issue., examples are protocols like TCP / IP, UDP, ATM, etc. Protocol is the basis of this subject. It also introduces many routing protocols to students. The main objective of the computer network subject in the curriculum is to explain how internetworking works, its application and management[2].

Computer network concepts and protocols make it difficult for students to imagine and understand how packages, flows, and protocols work during the theoretical teaching and learning process. Computer networks, as a subject, are very conceptual and technical. The computer networks' teaching and learning method requires students to know the fundamental concepts and their practical uses. Awareness of the subject relies on the creativity and visualization of the minds of students in the modern teaching process. Using a large amount of jargon is a major issue in teaching this subject. Students cannot grasp the term because of the jargon, contributing to low levels of teacher-student engagement in the classroom[3]. Much computer networking teaching transpires as a monologue of teachers in the classroom. Without practical experience, this topic cannot be completely understood[4].

Students can not only acquire theoretical knowledge, but also practical skills to configure and handle actual computer network situations while teaching basic and advanced computer network concepts such as subnetting, switching, routing and others. These functional skills are learned in education through the growth of the socalled laboratory[5]. The use of the laboratory should be done in a reduced group of students to obtain maximum availability to practice with different networking elements to acquire necessary skills. To achieve this objective in the real laboratory, the development of complex topology networks is needed, though it is costly in terms of time and economy.

In the learning of computer science, nearly all subjects require practical knowledge. There are also many subjects that require theoretical knowledge along with practical knowledge. A handful of technical topics are delivered using traditional classroom-based teaching and learning process and computer network is one of them. The numbers of traditional class learning in such subject can cause poor understanding among student population[6]. 


\section{$2 \quad$ Literature Review}

Over the last few years, the world has undergone the fourth industrial revolution. Working conditions are encouraged to develop quickly in the expectation that substantial benefits can be gained in the future. More than ever, conventional production processes are being automated and linked to other activities in the business. Data management, the management of big data into correct data, is one of the most significant factors in the Industry 4.0 environment. It is carried out using cyber-physical system (CPS), internet of things (IoT) and cloud computing. In order to get a new system in the future, the human profession is obliged to adjust and alter such that known positions are proposed. Staff need to learn to adjust and grow to cope with new circumstances and embrace and continually develop their performance by embracing the term life-learning process. Ultimately, higher efficiency, improved product quality and higher sales with reduced production time and cost are anticipated with the use of technology and human improvement. In addition, the term mass customization becomes increasingly important and demands a highly flexible manufacturing [7]. The word Industry 4.0 stands for the fourth industrial revolution, described as a new level of organization and control over all product life cycle value chains; it is increasingly geared towards individual consumer needs. Industry 4.0 is a visionary yet realistic concept, contained within it Internet of Things, Industrial Internet, Smart Manufacturing and Cloud-based Manufacturing[8].

All preparations must be made in facing industrial revolution 4.0 in which all industries are virtual-based in their relationships between humans, machines, data and everything else, which is known as IoT or the Internet of Things. Industry 4.0 is a very promising approach based on the integration of business and manufacturing processes, as well as the integration of all those interested in the company's value chain, namely suppliers and customers. Hereby, generic concepts from CyberPhysical Systems (CPS) and Industrial Internet of Things (IoT) emerge in industrial production systems[9].

Industry 4.0 is an evolving model for increasing the digitization and automation of the manufacturing system, as well as the development of digital value chains that enable goods and their ecosystems to interact with business partners. All production processes and in particular, the maintenance of systems and machines with all applicable technical documentation are taken into account in this digitalization process. The Industry 4.0 paradigm is the driving force behind the creation of a new generation of digital technical guidance, focused in particular on new display technologies such as Augmented and Virtual Reality, which take advantage of graphic and visual components that play a major role[10][11].

The use of technology to boost the experience of teaching and learning in the classroom has been suggested[12]. Augmented reality is one of these innovations, allowing a layer of virtual knowledge to be overlaid over actual scenes in order to enhance the user's understanding of reality. In an educational context, augmented reality has been shown to offer several advantages, namely increasing learning engagement and increasing awareness of several subjects especially when spatial skills are involved[13]. In an extended reality application, there are two kinds of content implemented: first is 
static, which is text, then dynamic, which is animation. No research project has to our knowledge, evaluated how this form of content, static or dynamic, could affect student learning experiences in applications of augmented reality. To decide how the form of content affects the learning experience of students, experimental design is required in which students interact with applications to study topics related to basic electronics courses using static and dynamic content[14].

According to Azuma, the term augmented reality refers to technology that improves the sensory experience of the real world by the user with a layer of computerassisted contextual knowledge[15]. In the Milgram Reality-Virtuality Continuum, these are closely related to Augmented Reality (AR) and Virtual Reality (VR) and represent different degrees of user immersion in environments where physical and digital objects coexist[16]. VR technology fully replaces the real world with a synonymous environment, while AR provides the user's context with virtual knowledge[15].

Recent advancements in wireless technology, mobile phone cameras, GPS and access to the Internet make AR accessible to everyone who owns a smartphone. As a consequence, in a number of subjects and contexts, many educators and developers are beginning to explore AR's capacity for teaching and learning. However only a few studies have so far attempted to measure the effects of AR on learning performance. The research presented here is the first field experiment on the impact of AR on the study of mathematical material, to the best of our knowledge[17]. In a real educational environment, [18] conducted a study with students with special educational needs. The learning content focuses on understanding currency, coins and banknotes and on managing them. In students with learning disabilities, unspecified learning difficulties, and attention deficit hyperactivity disorder, the findings showed a substantial improvement in the level of information and motivation.

An rise in the number of recent research studies on this subject was noticed by [19]. The utility of AR technology will increase in the near future with planned technological advances. Thus, their use will definitely be broader, and they will be based on further research. In turn, such future studies will provide further insights into its successful use in the field of education. Educators may also have more faith in their ability to use them.

In the era of the industrial revolution 4.0, there was a change in the manual use to visual use, especially the use of Augmented Reality technology. [20] conducted research on maintenance measures in the form of instructional texts, which are very commonly used in industrial fields. They replace this text into standard symbols that smartphones can read using augmented reality technology.

Likewise, with [21] who promoted the use of technology in education, namely by creating an Augmented Reality mobile game "Guardians of The Mo'o" for ESL students (English as a Second Language) to improve their cultural understanding, communication skills and also development. Language. According to [22] was designed and developed a set of inquiry-based Augmented Reality learning tools in chemistry courses, especially in micro-world learning to be able to properly visualize microstructures during the early stages of learning chemistry. With AR, students can control, combine, and interact with a 3D micro particle model using markers and carry out a series of investigation-based experiments. AR tools are put into practice at a 
junior high school in Shenzhen, China. And then [23] examined an augmented reality system for mobile devices that facilitates the visualization of 3D brain tumours in real time.

According to [24], educational applications sold as tools are often created with little or no input from educators or development specialists, and therefore are of little to no use. As a result of his research into the creation and exploration of the Evaluation Tool for Educational Applications (ETEA), a framework emerges that includes four factors: usability, efficiency, parental control, and security, can be an example of a solution that can benefit parents and current teachers. The aim, according to [25], is to provide a comprehensive overview of what is available on evaluation tools for educational apps for children by critically evaluating content from a variety of sources. A systematic literature review was conducted to accomplish this task, which included searching various electronic databases and internet sources for all English literature published after January 2010. Planning the study, locating important studies in the literature, critical examination of the literature, and summarizing and analysing the results were all part of the process and also using PRISMA. According to the findings of his study, many assessment methods are ineffective in assisting teachers and parents in accurately and quickly assessing the pedagogical potential of educational applications, and several are out of date and need to be revised. As a result, successful assessment methods are in high demand to assist parents and teachers in choosing educational applications.

There are still outstanding issues and difficulties in integrating digital technology into preschool and elementary education. At the system / platform level, on their research mainly refers to smart mobile devices and their corresponding mobile applications. These fields of robotics, mathematics, STEM, and literacy have shown to provide numerous opportunities for early childhood, especially for those who are expected to foster interest in computing from an early age. The key aim is to have a deeper understanding of how emerging technologies affect children's learning processes and their potential for early childhood education[26][27]. Computational thinking and programming are very important in the 21 st century at this time, through the application of technology that is appropriate to its development, the development of coding skills is increasingly possible, and the result can be in the form of advances in CT fluency or at least familiarity in young children. Given the tremendous success of smart mobile devices and the accompanying mobile applications, in research conducted by [28] who investigated the use of technology applied to Children of Preschool and Pre-Primary School Age. Children's favourite media is mobile devices, and their widespread use has spawned a new wave of so-called mobile applications or apps for use in educational settings. Despite the proliferation of apps claiming to educate children, there is a significant disparity in app quality. While apps can provide active, fun, and interesting context, the question is whether they align with children's educational needs. His research findings show that very few of the so-called "educational" applications that have been evaluated and tested can improve children's intelligence and improve their learning performance[29]. 


\section{$3 \quad$ Methodology}

In this study, the research methodology used includes the following stages:

\subsection{Envisioning phase (Problem identification)}

This was a phase where objectives, benefits and scope of the catalog were defined in writing. The objective of this phase was utilizing new technology in the field of education, especially the application of technology in learning method, development of animation teaching materials, and utilization of AR in computer networking devices.

\subsection{Planning phase (Planning)}

This was a phase where the catalog to be made was modelled, designed, and planned according to the desired objectives and benefits in the draft form. Marker design is also carried out which will be recorded in a catalog.

\subsection{Developing phase (Design)}

The stage where the draft is realized in the form of a product catalog. In this stage, a catalog containing markers from computer network devices will be created.

\subsection{Stabilizing phase (Testing)}

This was a phase where the application was tested in various conditions to identify existing shortcomings. In this stage the application will tested on student to identify the limitations of the AR catalog of the computer networking devices designed.

\subsection{Deploying phase (Implementation)}

This was a phase where the catalog product was used by users to obtain criticism and suggestions as well as possible next development steps:

\subsection{Evaluation phase (System evaluation)}

The evaluation stage consists of :

a) Determination of research samples

Evaluation of the use of this application was carried out on students of the information system study program, Sultan Syarif Kasim State Islamic University, Riau, Indonesia with a total of 31 students as a sample. 
b) Testing Research Instruments

SUS is a questionnaire consisting of 10 question items (Brooke, 1996) as shown in Table 1. The SUS questionnaire uses a 5-point Likert scale. Respondents were asked to give ratings "Strongly disagree", "Disagree", "Neutral", "Agree", and "Strongly agree" on 10 items of the SUS statement according to their subjective assessment. If the respondent feels that they do not find the right response scale, the respondent must fill in the middle point of the test scale (Brooke, 1996). Each statement item has a contribution score. Each item's contribution score will range from 0 to 4.For items $1,3,5,7$, and 9 the contribution score is the po-side of the scale minus 1. For items $2,4,6,8$, and 10 , the contribution score is- is 5 minus the scale position. Multiply the total contribution score by 2.5 to get the overall system usability score.

Table 1. SUS Questionnaire

\begin{tabular}{|c|l|}
\hline No & \multicolumn{1}{|c|}{ Questionnaire } \\
\hline 1 & I think I would like to use this apps frequently. \\
\hline 2 & I found the apps unnecessarily complex. \\
\hline 3 & I thought the apps was easy to use. \\
\hline 4 & I think that I would need the support of a technical person to be able to use this apps. \\
\hline 5 & I found the various functions in this apps were well integrated. \\
\hline 6 & I thought there was too much inconsistency in this apps. \\
\hline 7 & I would imagine that most people would learn to use this apps very quickly. \\
\hline 8 & I found the apps very cumbersome to use. \\
\hline 9 & I felt very confident using the apps. \\
\hline 10 & I needed to learn a lot of things before I could get going with this apps. \\
\hline
\end{tabular}

c) Data analysis using SUS

Evaluation of AR application using the System Usability Scale: In this study, data analysis was performed using the SUS method. The System Usability Scale (SUS) method is a technique used to test the usability of an application[30]. SUS was developed as a "quick and dirty" usability measurement. SUS is a questionnaire that can be used to measure the usability of a computer system according to user's subjective point of view. SUS was developed by John Brooke since 1986[31]. The SUS instrument consists of 10 question items. To date, SUS is widely used to measure usability and show several advantages, such as:

1. SUS is easy to use since the result is a score of $0-100$.

2. SUS is easy to use, does not require complex calculation.

3. SUS is free, no additional cost needed.

4. SUS has been proven to be valid and reliable, even with a small sample size.

The test scale ranges from 1 (strongly disagree) to 5 (strongly agree).

SUS Score Calculation Method: The calculation of AR application testing results with the SUS instrument was performed by following several rules: Each statement item has a contribution score. Each item contribution score ranged from 0 to 4 . For 
each statement with an odd number, namely 1, 3, 5, 7 and 9, respondent's answer scale is reduced by 1 . For each statement with even number, namely $2,4,6,8$, and 10 , respondent's answer scale is reduced by 5 . To obtain the overall value of the usability system, the total contribution score is multiplied by a value of 2.5 .

The following is the SUS score calculation formula:

SUS Score $=((R 1-1)+(5-R 2)+(R 3-1)+(5-R 4)+(R 5-1)+(5-R 6)+$ $(R 7-1)+(5-R 8)+(R 9-1)+(5-R 10)) * 2.5)$

Scores in SUS

The results of the SUS Score assessment is in the following figure:

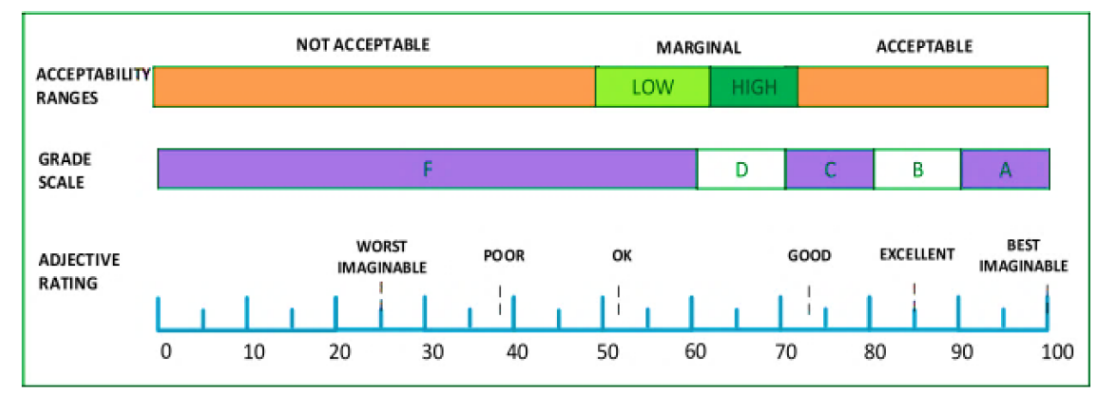

Fig. 1. Scores in SUS

Based on the assessment of the scores on the SUS, there are 3 ratings, namely:

1. Acceptability Ranges is the result with the following range:

- Not Acceptable 0-50

- Marginal 50-70

- Acceptable 70-100

2. Grade Scale

$$
\begin{aligned}
& -A=80.3-100 \\
& -B=68-80.3 \\
& -C=68 \\
& -D=51-68 \\
& -F=0-51
\end{aligned}
$$

3. Adjective Ratings

$$
\begin{aligned}
& \text { - Best Imaginable }=85-100 \\
& - \text { Excellent }=74-85 \\
& - \text { Good }=53-74 \\
& - \text { Ok }=39-53 \\
& - \text { Poor }=25-39 \\
& - \text { Worst Imaginable }=0-25
\end{aligned}
$$




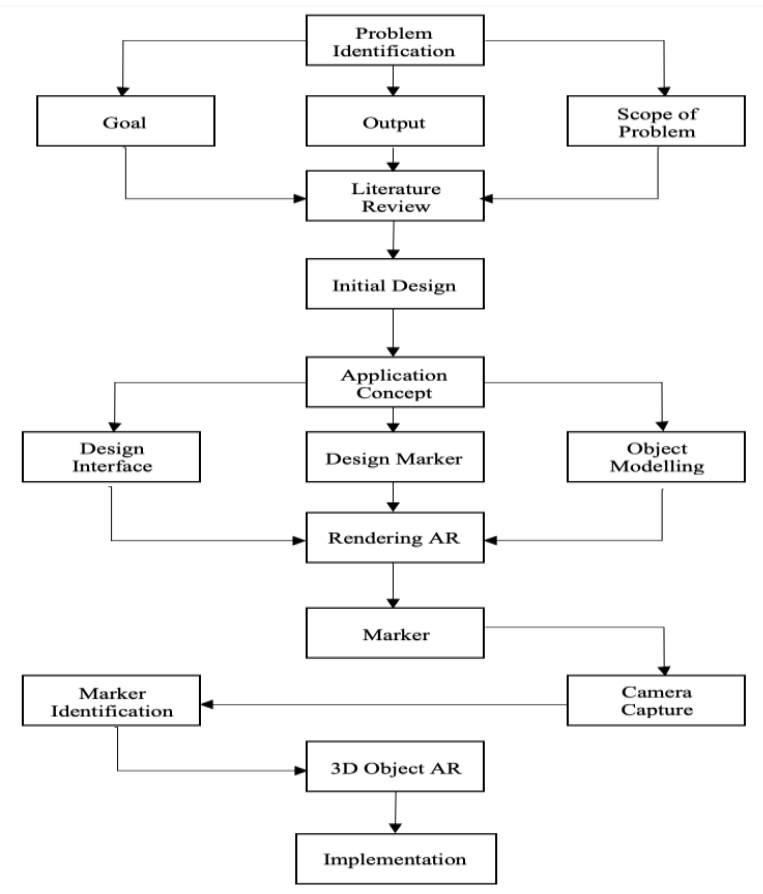

Fig. 2. Research Framework

\section{$4 \quad$ Result and Discussion}

\subsection{Augmented reality application for computer network device}

This learning media in the form of an Android application in its use must be installed first on an Android smartphone and used together with the marker images on the books that have been provided. The AR technology used to develop this media was marker-based AR technology, meaning that to see virtual objects in the form of $3 \mathrm{D}$ models in this application there must be a marker image object that was scanned using a smartphone camera. The marker image was called the "target marker". With existing marker-based AR technology, the designated object can only be loaded on the screen from one marker and another marker must be added so that the same object load on the screen again. This creates a problem where relevant markers should be extracted and displayed on the screen so that several objects can be loaded[32]. The exploitation of AR technology in the development of learning media provides distinct experience, both for teachers and students. AR can be used to bridge the gap between practical learning and theoretical practice along with real and virtual components combined to make unique learning experience. In the systematic review of studies and applications, the use of AR in education is shown to be effective for several purposes, such as better learning performance, motivation learning, student involvement and 
positive attitudes[33]. According to[34], what limits the use of VR or AR technology in educational settings is not the use of technology itself, but how these technologies are used and how students learn. Virtual learning experience is not merely intended to obtain knowledge; therefore, it is necessary to design a learning environment from a constructivist approach to obtain the full benefits of learning.

Splash Screen Display (SSD): When the application is opened, the first thing that will appear is the splash screen page. This design is the basis for the introduction of applications in general to show the name of the application.

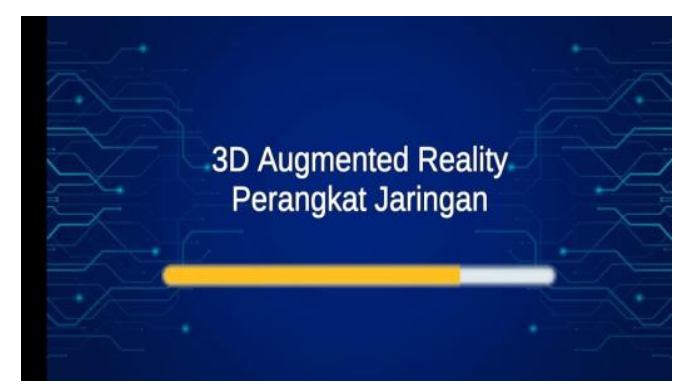

Fig. 3. Splash Screen Page

The Main Menu display will appear after the splash screen page. Menu options are used by users to select the menu item that the user wants. The main menu display consists of 3 buttons namely Start, Guide and About

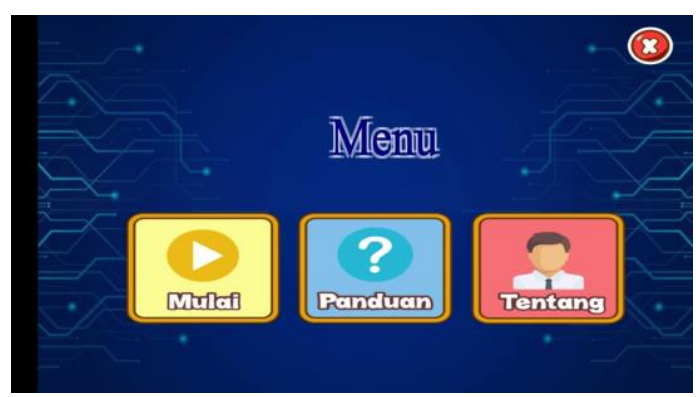

Fig. 4. Menu Page

Network Interface Card (NIC): Open the "Start" menu, then point the smartphone camera at the NIC marker. The hardware related 3D image will appear. Then click information to find out detailed information regarding the image about the NIC. 


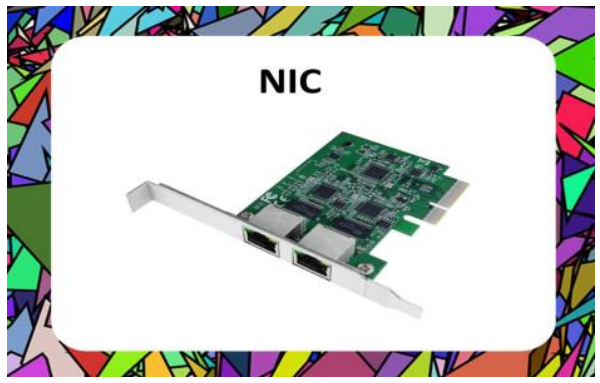

Fig. 5. Marker NIC

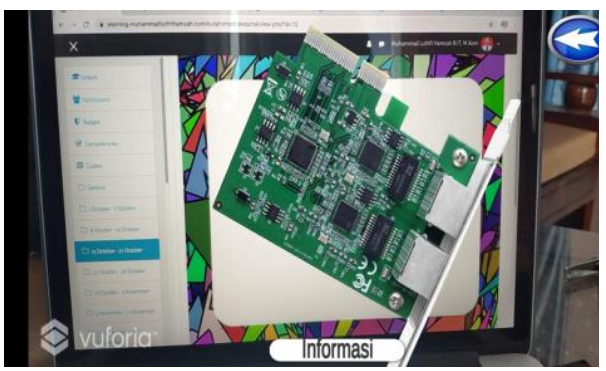

Fig. 7. AR for NIC

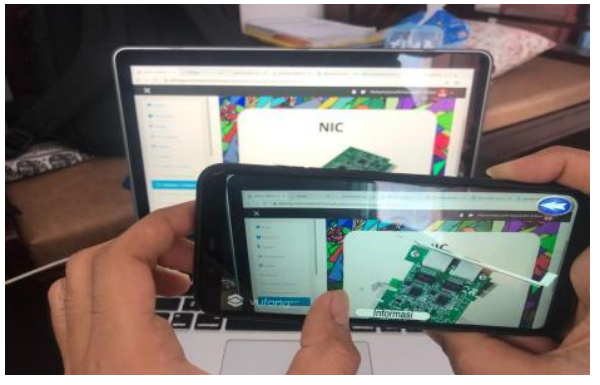

Fig. 6. Smartphone Scanning Marker

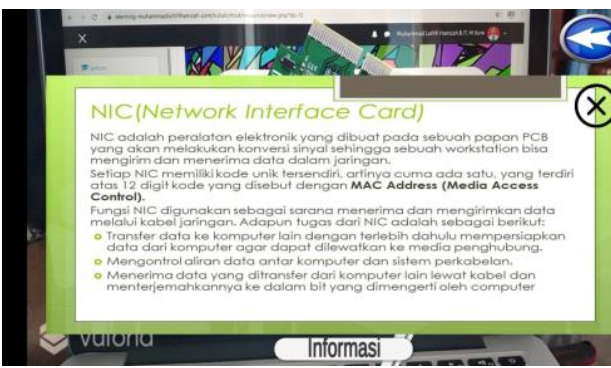

Fig. 8. Information NIC

RJ45: To open AR information for RJ45, click the "Start" menu, then point the smartphone camera at the RJ45 marker. The hardware related 3D image will appear. Then click Information to find out detailed information about the RJ45 image.

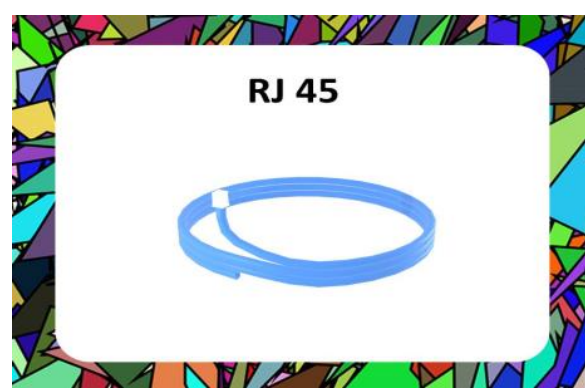

Fig. 9. Marker RJ45

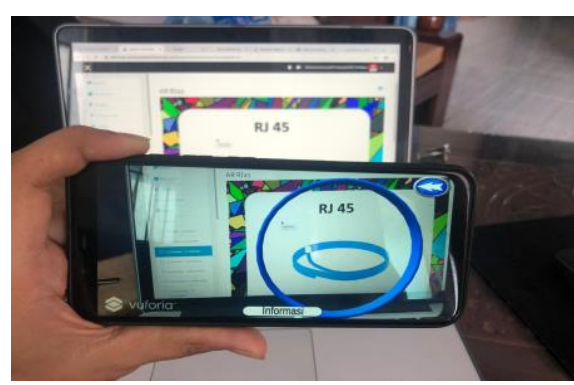

Fig. 10.Smartphone Scanning Marker 


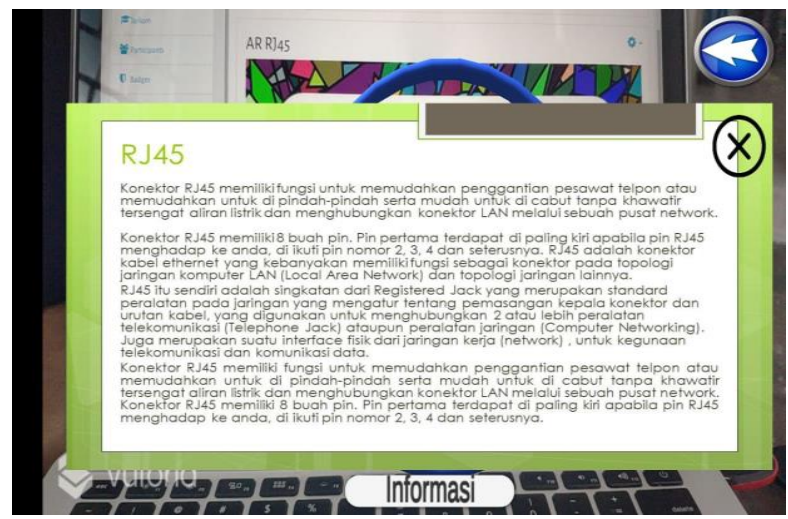

Fig. 11.Information about RJ45 Device

Router: To open AR information for the Router by clicking the "start" menu, then point the smartphone camera at the Router marker. After pointing the smartphone camera at the marker, then a 3D image related to the hardware appears, then click the information to find out detailed information regarding the image about the Router.

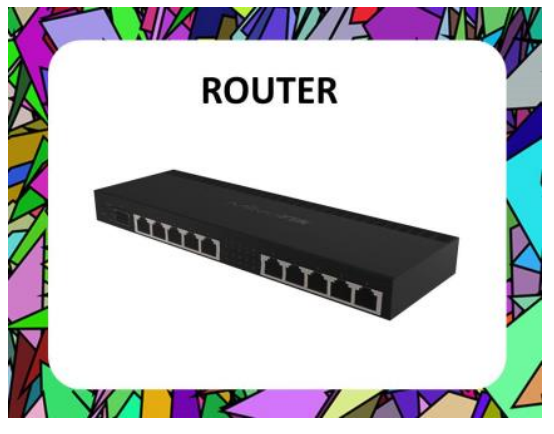

Fig. 12.Router Marker

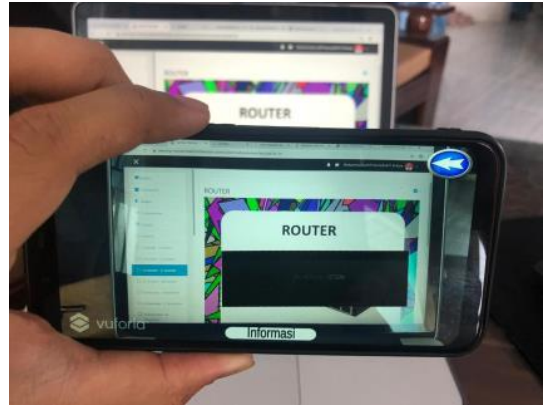

Fig. 13.Smartphone Scanning Marker

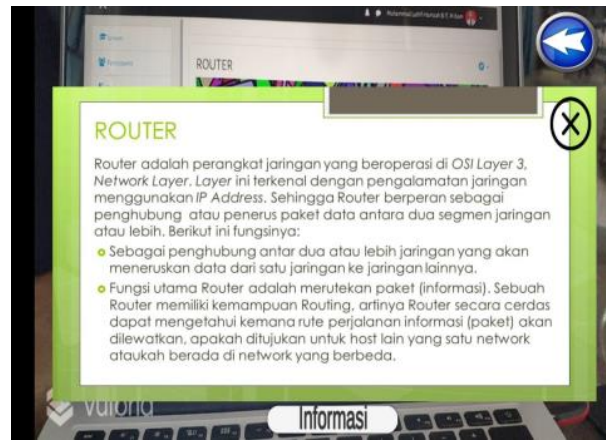

Fig. 14. Information of Router Device 
Switch: To open AR information for the Switch, click the "start" menu, then point the smartphone camera at the switch marker. After pointing the smartphone camera at the marker, a 3D image related to the hardware appears, then click the information to find out detailed information regarding the image about the Switch.

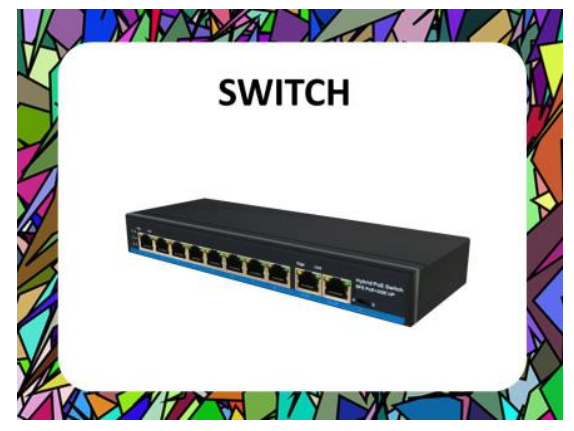

Fig. 15.Switch Marker

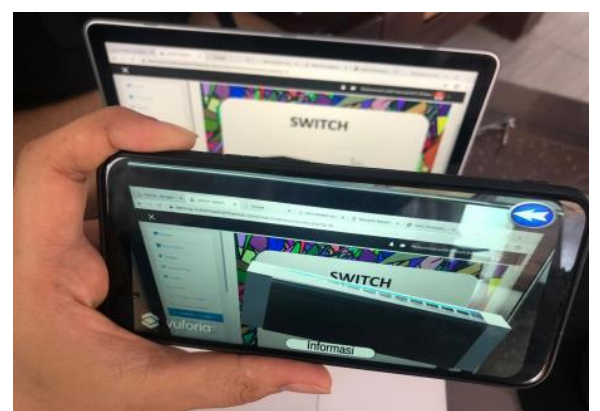

Fig. 16.Smartphone Scanning Marker

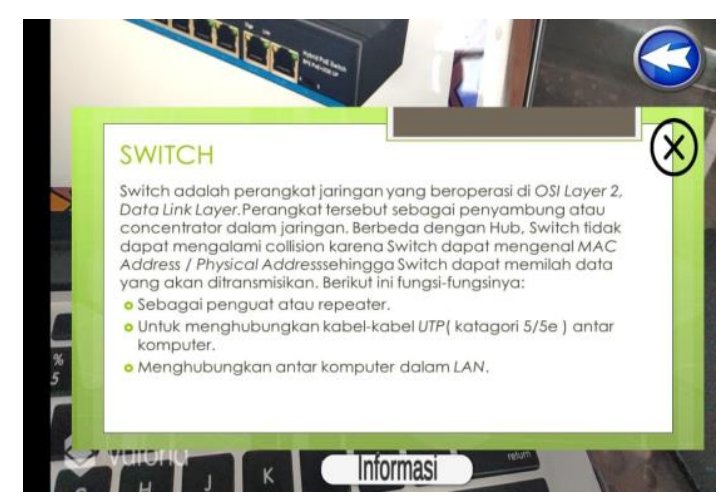

Fig. 17.Information of Switch Device

Hub: To open AR information for the Hub by clicking the "start" menu, then pointing the smartphone camera to the hub marker. After pointing the smartphone camera at the marker, then a 3D image related to the hardware appears then click the information to find out detailed information regarding the image about Hub. 


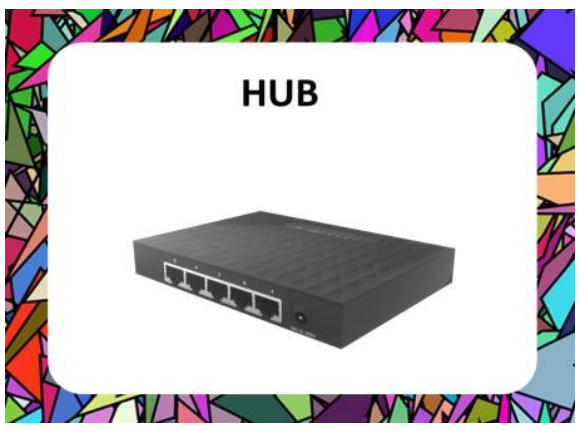

Fig. 18.Hub Marker

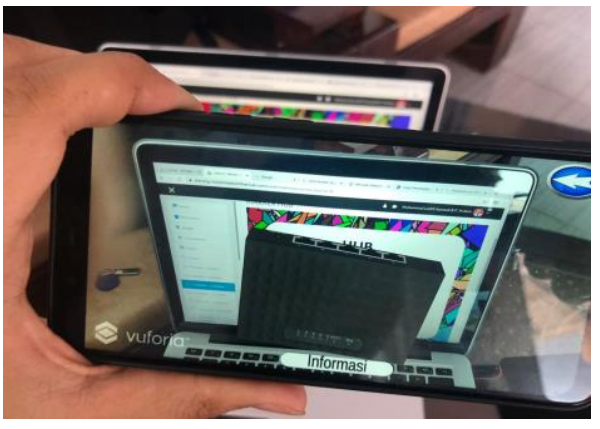

Fig. 19.Smartphone Scanning Marker

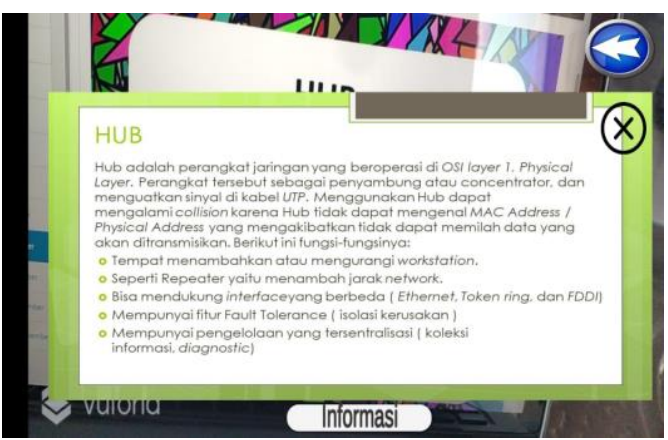

Fig. 20.Information of Hub Device

\subsection{Application Evaluation Results (AER)}

Validity and reliability test: To analyse the validity of the research instrument, the first step is to test the validity and reliability using SPSS with the following results:

Table 2. Validity and Reliability Test Results

\begin{tabular}{|c|c|c|}
\hline Questionnaire & Corrected Item-Total Correlation & \multirow{2}{*}{ Cronbach's Alpha } \\
\hline R1 & .642 \\
\hline R2 & .584 \\
\hline R3 & .454 \\
\hline R4 & .385 \\
\hline R5 & .515 \\
\hline R6 & .417 & \multirow{2}{*}{.819} \\
\hline R7 & .572 \\
\hline R8 & .525 \\
\hline R9 & .528 & \\
\hline & .405 & \\
\hline
\end{tabular}


Based on table 2. it can be seen that the overall Corrected Item Total Correlation (Rcount) value $>0.3$, it can be concluded that all SUS question items are valid and Cronbach's Alpha value> 0.7 , so it can be stated that the questionnaire in this study is Reliable.

SUS score analysis: The final scale score is obtained based on the rules of the System Usability Scale (SUS) method. The calculation of the 31 respondents obtained a total value of 2435 . Then the average value or SUS Score obtained was 78.5. The SUS method provides stipulation with three assessments, namely Acceptability, Grade Scale and Adjective Rating. It is used to see the extent of students in using AR Application of Universitas Islam Negeri Sultan Syarif Kasim Riau to support learning activities. The assessment was performed based on three categories of the Acceptability aspect, namely "not acceptable", "marginal" and "acceptable". While the Grade Scale aspect had six scales, namely A, B, C, D, and F and the Adjective Rating consisted of "worst imaginable", "poor", "okay", "good", "excellent" and "best imaginable". Based on the results of the calculation of 31 respondents, the average value was 78.5 .

1. Acceptability Ranges: the above mean value is Acceptable.

2. Grade Scale: the above mean value falls into Scale B.

3. Adjective Ratings: the above mean value is considered Excellent.

From these results it can be stated that the AR application can be used easily by users so that it is expected to support lecture activities.

\section{Conclusion}

Based on the results of research at the system functionality stage of the development of learning media recognizing computer network devices using augmented reality technology, it can be concluded as follows: The application of augmented reality recognizes computer network devices capable of realizing the virtual world to the real world, can display objects $2 \mathrm{D}$ images become $3 \mathrm{D}$ objects, so the learning method is not monotonous and students are encouraged to find out more, such as knowing the shape and visualization of the name of a computer network device that resembles the original form and information from each of these devices. And also, after evaluating the usability with SUS of 31 respondents and it can be concluded that this AR application can be accepted by these students in its use with SUS Score obtained was 78.5. The limitation in this study is limited to only the application of AR applications to one subject and evaluation is only used at one university.

\section{References}

[1] G. Valentine and S. L. Holloway, "A window on the wider world? Rural children's use of information and communication technologies," J. Rural Stud., vol. 17, no. 4, pp. 383-394, 2001, https://doi.org/10.1016/s0743-0167(01)00022-5. 
[2] H. Xie and Q. Zhong, "Design of basic computer teaching mode based on blended learning," Proc. 14th IEEE Int. Conf. High Perform. Comput. Commun. HPCC-2012 - 9th IEEE Int. Conf. Embed. Softw. Syst. ICESS-2012, vol. 0, pp. 1673-1676, 2012, https://doi.org/10.1109/hpcc.2012.247.

[3] P. H. M. Gurgel, L. H. C. Branco, E. F. Barbosa, and K. R. L. J. C. Branco, "Development of a practical computer network course through netkit virtualization tool," Procedia Comput. Sci., vol. 18, pp. 2583-2586, 2013, https://doi.org/10.1016/j.procs.2013.05.445.

[4] M. Vinay and S. Rassak, "A Technological Framework for Teaching-Learning Process of Computer Networks to Increase the Learning Habit,” Int. J. Comput. Appl., vol. 117, no. 4, pp. 1-4, 2015, https://doi.org/10.5120/20539-2904.

[5] I. A. Garcia, C. L. Pacheco, and J. N. Garcia, "Enhancing education in electronic sciences using virtual laboratories developed with effective practices," Comput. Appl. Eng. Educ., vol. 22, no. 2, pp. 283-296, 2014, https://doi.org/10.1002/cae.20554.

[6] Z. Ran, "Exploration on the Key Issues of Practical Teaching Reform of Computer Network," Energy Procedia, vol. 17, pp. 1914-1919, 2012, https://doi.org/10.1016/j.egypro. 2012.02.332.

[7] M. Trstenjak and P. Cosic, "Process Planning in Industry 4.0 Environment," Procedia Manuf., vol. 11, no. June, pp. 1744-1750, 2017, https://doi.org/10.1016/j.promfg. 2017.07.303.

[8] S. Vaidya, P. Ambad, and S. Bhosle, "Industry 4.0 - A Glimpse," Procedia Manuf., vol. 20, pp. 233-238, 2018, https://doi.org/10.1016/j.promfg.2018.02.034.

[9] A. Rojko, "Industry 4.0 concept: Background and overview," Int. J. Interact. Mob. Technol., vol. 11, no. 5, pp. 77-90, 2017, https://doi.org/10.3991/ijim.v11i5.7072.

[10] T. D. Oesterreich and F. Teuteberg, "Understanding the implications of digitisation and automation in the context of Industry 4.0: A triangulation approach and elements of a research agenda for the construction industry," Comput. Ind., vol. 83, pp. 121-139, 2016, https://doi.org/10.1016/j.compind.2016.09.006.

[11] M. I. Qureshi, N. Khan, H. Raza, A. Imran, and F. Ismail, "Digital Technologies in Education 4. 0. Does it Enhance the Effectiveness of Learning? A Systematic Literature Review,” Int. J. Interact. Mob. Technol., vol. 15, no. 04, pp. 31-47, 2021. https://doi.org/10.3 991/ijim.v15i04.20291

[12] M. L. Hamzah, K. Rukun, F. Rizal, A. A. Purwati, Hamzah, and Zarnelly, "A review of increasing teaching and learning database subjects in computer science," Espacios, vol. 40, no. 26, 2019.

[13] R. Situmorang, C. Kustandi, S. Maudiarti, R. Widyaningrum, and D. Ariani, "Entrepreneurship Education Through Mobile Augmented Reality for Introducing SMEs in Higher Education,” Int. J. Interact. Mob. Technol., vol. 15, no. 03, p. 17, 2021, https://doi.org/10. 3991/ijim.v15i03.18437.

[14] C. Diaz, M. Hincapié, and G. Moreno, "How the Type of Content in Educative Augmented Reality Application Affects the Learning Experience," Procedia Comput. Sci., vol. 75, no. Vare, pp. 205-212, 2015, https://doi.org/10.1016/j.procs.2015.12.239.

[15] M. Billinghurst, A. Clark, and G. Lee, "A survey of augmented reality," Found. Trends Human-Computer Interact., vol. 8, no. 2-3, pp. 73-272, 2014, doi: 10.1561/1100000049.

[16] P. Milgram and F. Kishino, “A Taxonomy of Mixed Reality Visual Displays," IEICE Trans. Inf. Syst., vol. E77-D, no. 12, pp. 1-15, 1994.

[17] P. Sommerauer and O. Mueller, "Augmented Reality in Informal Learning Environments: Investigating Short-term and Long-term Effects," Proc. 51st Hawaii Int. Conf. Syst. Sci., vol. 9, pp. 1423-1430, 2018, https://doi.org/10.24251/hicss.2018.176. 
[18] A. Cascales-Martínez, M. J. Martínez-Segura, D. Pérez-López, and M. Contero, "Using an augmented reality enhanced tabletop system to promote learning of mathematics: A case study with students with special educational needs," Eurasia J. Math. Sci. Technol. Educ., vol. 13, no. 2, pp. 355-380, 2017, https://doi.org/10.12973/eurasia.2017.00621a.

[19] M. Akçayir, G. Akçayir, H. M. Pektaş, and M. A. Ocak, "Augmented reality in science laboratories: The effects of augmented reality on university students' laboratory skills and attitudes toward science laboratories," Comput. Human Behav., vol. 57, pp. 334-342, 2016, https://doi.org/10.1016/j.chb.2015.12.054.

[20] G. W. Scurati, M. Gattullo, M. Fiorentino, F. Ferrise, M. Bordegoni, and A. E. Uva, "Converting maintenance actions into standard symbols for Augmented Reality applications in Industry 4.0," Comput. Ind., vol. 98, pp. 68-79, 2018, https://doi.org/10.1016/j.compind. 2018.02.001.

[21] Y. Liu, D. Holden, and D. Zheng, “Analyzing students' Language Learning Experience in an Augmented Reality Mobile Game: An Exploration of an Emergent Learning Environment," Procedia - Soc. Behav. Sci., vol. 228, no. June, pp. 369-374, 2016, https://doi.org/10.1016/j.sbspro.2016.07.055.

[22] S. Cai, X. Wang, and F. K. Chiang, "A case study of Augmented Reality simulation system application in a chemistry course," Comput. Human Behav., vol. 37, pp. 31-40, 2014, https://doi.org/10.1016/i.chb.2014.04.018.

[23] Q. Shan, T. E. Doyle, R. Samavi, and M. Al-Rei, "Augmented Reality Based Brain Tumor 3D Visualization,” Procedia Comput. Sci., vol. 113, pp. 400-407, 2017, https://doi.org/10. 1016/j.procs.2017.08.356.

[24] S. Papadakis, J. Vaiopoulou, M. Kalogiannakis, and D. Stamovlasis, "Developing and exploring an evaluation tool for educational apps (E.T.E.A.) targeting kindergarten children," Sustain., vol. 12, no. 10, pp. 1-10, 2020, https://doi.org/10.3390/su12104201.

[25] S. Papadakis, "Tools for evaluating educational apps for young children: a systematic review of the literature," Interact. Technol. Smart Educ., 2020, doi: https://doi.org/10.11 08/ITSE-08-2020-0127.

[26] P. Dorouka, S. Papadakis, and M. Kalogiannakis, "Tablets and apps for promoting robotics, mathematics, STEM education and literacy in early childhood education," Int. J. Mob. Learn. Organ., vol. 14, no. 2, pp. 255-274, 2020, https://doi.org/10.1504/ijmlo.2020. 10026334.

[27] S. Papadakis, "Robots and Robotics Kits for Early Childhood and First School Age," Int. J. Interact. Mob. Technol., vol. 14, no. 18, pp. 34-56, 2020, https://doi.org/10.3991/ijim. v14i18.16631.

[28] S. Papadakis, "Apps to Promote Computational Thinking Concepts and Coding Skills in Children of Preschool and Pre-Primary School Age," Mob. Learn. Appl. Early Child. Educ., pp. 101-121, 2020, doi: https://doi.org/10.4018/978-1-7998-1486-3.ch006 .

[29] S. Papadakis and M. Kalogiannakis, "A Research Synthesis of the Real Value of SelfProclaimed Mobile Educational Applications for Young Children," Mob. Learn. Appl. Early Child. Educ., pp. 1-19, 2020, https://doi.org/10.4018/978-1-7998-1486-3.ch001.

[30] M. Mol et al., "Dimensionality of the system usability scale among professionals using internet-based interventions for depression: A confirmatory factor analysis," BMC Psychiatry, vol. 20, no. 1, pp. 1-10, 2020, doi: 10.1186/s12888-020-02627-8.

[31] D. Pal and V. Vanijja, "Perceived usability evaluation of Microsoft Teams as an online learning platform during COVID-19 using system usability scale and technology acceptance model in India," Child. Youth Serv. Rev., vol. 119, p. 105535, 2020, https://doi.org/10.1016/j.childyouth.2020.105535. 
[32] S. Jung, J. G. Song, D. J. Hwang, J. Y. Ahn, and S. Kim, "A study on software-based sensing technology for multiple object control in AR video," Sensors (Switzerland), vol. 10, no. 11, pp. 9857-9871, 2010, https://doi.org/10.3390/s101109857.

[33] F. Saltan and Ö. Arslan, "The use of augmented reality in formal education: A scoping review," Eurasia J. Math. Sci. Technol. Educ., vol. 13, no. 2, pp. 503-520, 2017, https://doi.org/10.12973/eurasia.2017.00628a.

[34] J. Martín-Gutiérrez, C. E. Mora, B. Añorbe-Díaz, and A. González-Marrero, "Virtual technologies trends in education," Eurasia J. Math. Sci. Technol. Educ., vol. 13, no. 2, pp. 469-486, 2017, https://doi.org/10.12973/eurasia.2017.00626a.

\section{$7 \quad$ Authors}

Muhammad Luthfi Hamzah, B.IT, M.Kom is lecturer at Information System Department, Faculty Science and Technology, Universitas Islam Negeri Sultan Syarif Kasim Riau, Indonesia, Scopus ID : 57211346531.

Prof. Dr. Ambiyar, M.Pd is a Professor at Faculty Engineering, Universitas Negeri Padang, Indonesia. Scopus ID: 57207299138.

Dr. Fahmi Rizal, M.Pd, MT is a Lecturer at Faculty Engineering, Universitas Negeri Padang, Indonesia. Scopus ID: 57205239674.

Prof. Dr. Wakhinudin Simatupang, M.Pd is a Professor at Faculty Engineering, Universitas Negeri Padang, Indonesia. Scopus ID: 57196371509.

Dr. Dedy Irfan, M.Kom is a Lecturer at Faculty Engineering, Universitas Negeri Padang, Indonesia. Scopus ID: 57201558923.

Dr. Refdinal, MT is a Lecturer at Faculty Engineering, Universitas Negeri Padang, Indonesia. Scopus ID: 57205217215.

Article submitted 2021-02-12. Resubmitted 2021-03-18. Final acceptance 2021-03-19. Final version published as submitted by the authors. 